\title{
Formation of Multiple Phase Microstructure and Wear Investigation on Treated AISI 904L SS by Low Temperature Ion Nitriding Process
}

\author{
Ram.Subbiah ${ }^{1 *}$, N.Sateesh ${ }^{1}$, S.K.Singh ${ }^{1}$, S.Ravi Sekhar ${ }^{1}$, B.Tanya ${ }^{1}$, A.Anitha Lakshmi $^{1}$ \\ ${ }^{1}$ Mechanical Engineering Department, Gokaraju Rangaraju Institute of Engineering \& Technology, Hyderabad, India
}

\begin{abstract}
In industries, components have to operate under extreme prerequisites such as high load, speed, temperature and at a chemical environment. The materials are selected by commercial availability, cost and by considering by their properties like strength, hardness etc. AISI $904 \mathrm{~L}$ is a high alloy stainless steel with low carbon content material having poor hardness on the surface and negative wear properties. Many of the engineering failures are due to fatigue, corrosion and poor wear resistance which are initiated in its surface. This causes cracks in the surface which reduces the life of the material. Also the surfaces of the materials are caused by severe thermal, chemical and shock loads. Chosen for this work, AISI 904L materials were subjected to plasma or ion - nitriding process and were treated to 3 different timing parameters like 24 hrs, $48 \mathrm{hrs}$ and $72 \mathrm{hrs}$ respectively, maintaining constant temperature of $650^{\circ} \mathrm{C}$. Among the availability of other nitriding process like gas and liquid nitriding, plasma nitriding gives good dimensional stability, uniform treatment, less distortion, uniform case depth irrespective towards size and shape of the specimen. For analyzing the wear properties, a pin on disc machine is utilized making the pin to get weared on disc against a load of $100 \mathrm{~N}$ at a speed of $1000 \mathrm{rpm}$. Finally the metallographic studies were done by Scanning Electron Microscopic analysis.
\end{abstract}

\section{Introduction}

Stainless steels are modern materials. Ever since they became available to industries, their use has constantly extended into new applications. This process continues even today. To make successful use of the stainless steels, in wear resistant applications, it's necessary to understand the properties, their capabilities regarding corrosion resistance, the supply of product forms and surface finishes stainless steels are getting used for both corrosion and therefore the heat resisting applications[13]. Stainless steels are known for resistance to corrosion and marking, low maintenance, relative in expense. and familiar luster make it a perfect base material for a number of economic applications. The usage of stainless steels is compared with that of carbon steels but exhibits a gentle growth, in contrast to the constructional steels and their properties in many cases relatively unfamiliar to the designer.

Stainless steel is $100 \%$ recyclable. In fact, over $50 \%$ of new stainless steel is made from remelted scrap metal, rendering it a fairly eco-friendly material [4-6]. AISI 904L stainless steel can be used in excessive temperature applications and enhance their properties, with steadiness to dimensions. To make successful use of the AISI 904L stainless steel in wear resistant applications and for excessive temperature applications, its mechanical properties needs to be improved, with stabilityindimensions.

AISI 904L SS are used for heat resisting and resistance to corrosion applications. These steels satisfy the requirement in mixture with accurate mechanical houses and manufacturing traits and for this reason make it an crucial tool for the designers [7, 8]. AISI 904L Stainless steels have resistance to corrosion and staining, low maintenance, relative less expensive and familiar luster make it an ideal base material for a host of business functions $[9,10]$. Though these stainless steels characterize a low share of the complete amount of metal produced, they have a technological and financial significance because they are the key materials for chemical, petroleum, manner and strength industries. Austenite is formed though stable austenitizing elements such as $\mathrm{Ni}$ and $\mathrm{Mn}$ etc. These steels keep austenitic structure even at ambient temperature. Austenitic stainless steels are efficiently nonmagnetic in the annealed condition and can be hardened solely by cold working $[11,12]$. Some ferromagnetism may be observed due to cold working or welding. They commonly have sensible cryogenic and excessive temperature energy properties. Chromium content is between 17.5 to $25 \%$ and $\mathrm{Ni}$ less than $35 \%$.Typical application for the a number grades includes tanks, storage vessels and pipe work for corrosive liquids,

* Corresponding author: ram4msrm@gmail.com 
furnace and catalytic converter components, tanks, stress vessels, brilliant heaters, compensators and growth bellows. The excessive levels of chromium make a contribution to the first-rate wear behavior in austenitic stainless steel, making it suitable for use in submarines and nuclear power plant [13-15].

\section{Experimental Procedures}

\subsection{Material Preparation}

AISI 904L material containing composition of $0.02 \% \mathrm{C}$, $2 \%$ Mn. $1 \%$ Si, $0.04 \%$ P, $19 \%$ Cr, $0.03 \%$ S, $23 \%$ Ni, 3\% $\mathrm{Mb}$, Remaining $\mathrm{Fe}$ were utilized in the investigations, the composition is shown in Table 1were prepared in circular shaped rods and discs. The sample having 100 $\mathrm{mm}$ in diameter, $10 \mathrm{~mm}$ thickness were utilized as disc material and a diameter of $8 \mathrm{~mm}$ and length is $30 \mathrm{~mm}$ were utilized as pin material. Three samples of these treated steels were exposed to plasma nitriding process. Prior before the wear test, the samples were cleansed ultrasonically and dried and also to maintain a strategic distance from finger contact [16]. Before plasma nitrided, the samples were sand impacted, etched in $12 \%$ $\mathrm{H}_{2} \mathrm{So}_{4}$ for 15 minutes.

\subsection{Process Performed}

The plasma nitriding processes were done in a bell type heater shown in the Fig 2 for about 24 hours, 48 hours, 72 hours respectively. Utilizing a standard pin on disc machine shown in the Fig 3, with the test pin turned at $1000 \mathrm{rpm}$, with steady load of $100 \mathrm{~N}$, to a constant time of 7 minutes [17]. The wear rates were determined by deciding the weight reduction and the time were recorded when the test is before and after test [21-23].

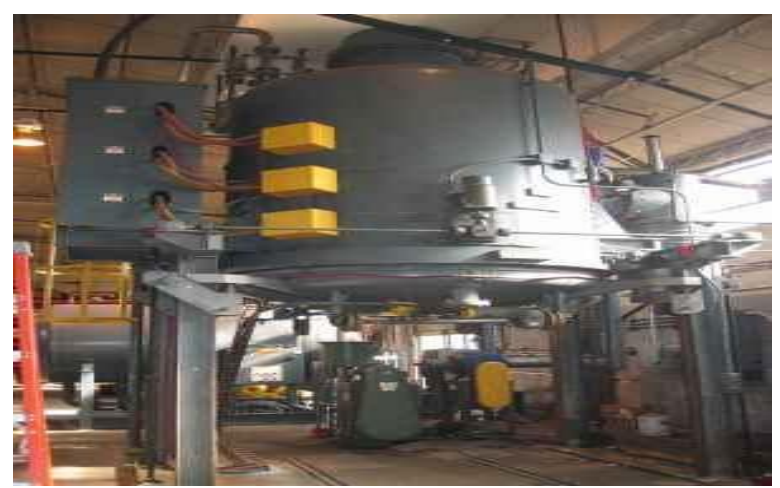

Fig 1. Plasma Nitriding Furnace Used

Plasma-Nitriding is an advanced surface hardness method which includes nitrogen atoms diffused into the metal at a plasma environment. Plasma nitriding is carried out in the location of odd glow discharge the place the work piece to be plasma nitrided is absolutely blanketed with glow and the voltage and contemporary will increase simultaneously. The work piece themselves become heated via the switch of strength associated with the action of ionic bombardment [18-20].

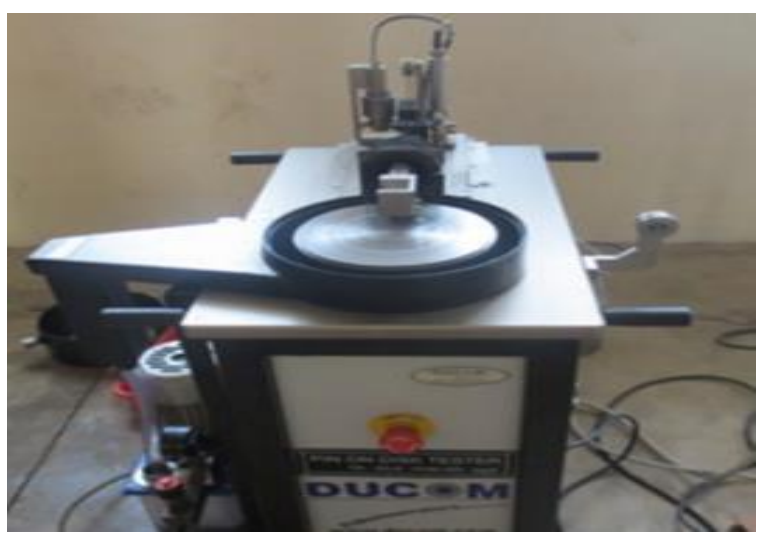

Fig 2. Pin on Disc Tribometer Used

\section{Results \& Discussions}

\subsection{Scanning Electron Microscope Results}

Fig 3 determines the scanning electron microscopy of Untreated AISI 904L sample. The peel of material are more, as the untreated samples was subjected to load of 100 N. Fig 4 shows the microstructure of sample subjected to $24 \mathrm{hrs}$ of treatment. Plasma ion nitrides were diffused at a process temperature of $650^{\circ} \mathrm{C}$ produced nitrogen expanded austenite layer with thickness of $2 \mu \mathrm{m}$ and average hardness of about 713Hv.[14-16]

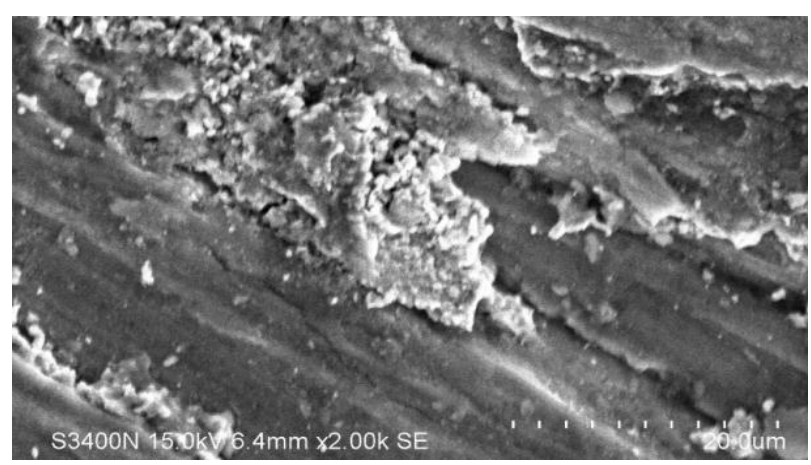

Fig 3. Untreated AISI 904L Sample after Wear

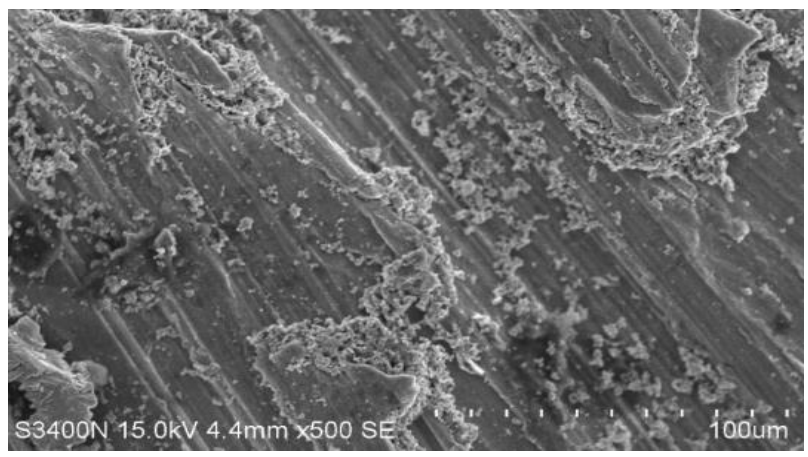

Fig 4. Plasma Nitrided 24 hrs Sample after Wear

Fig 5 shows the microstructures were composed of chromium nitrides treated to $48 \mathrm{hrs}$. It was noted that AISI 904L stainless steels was modified with the aid of low-strain-plasma-nitrided at same temperatures. The 
end results confirmed that the phase composition effect and the microhardness profiles of the nitride layers were improved. Fig 6 shows the samples treated at a temperature for $72 \mathrm{hrs}$, has the improved austenite section showing the formation of $\mathrm{CrN}$ phases [17-20]. The case depth of the nitrided layers increased with time of treatment. The hardness value of sample treated to 48 hrs was found to be $892 \mathrm{HV}$ and hardness upto $1021 \mathrm{HV}$ for the sample treated to $72 \mathrm{hrs}$.

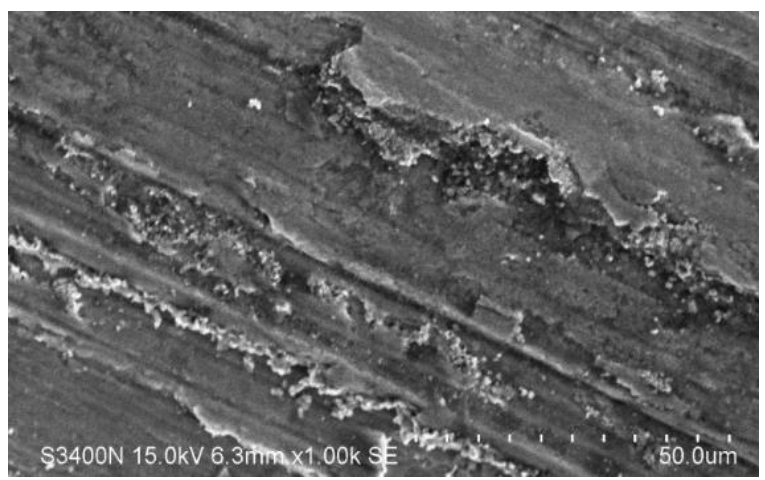

Fig 5. Plasma Nitrided 48 hrs Sample after Wear

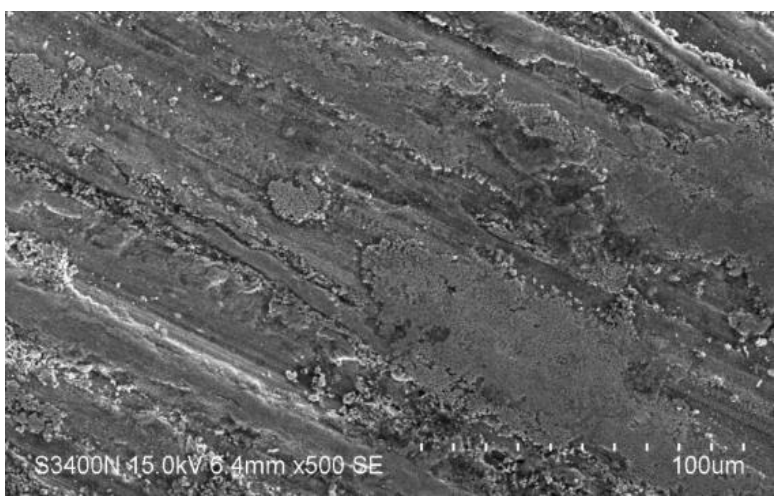

Fig 6. Plasma Nitrided 72 hrs Sample after Wear

\section{Conclusion}

One of the best quality surface-engineering technology is low temperature energetic display screen-plasmanitriding that can be used to enhance the put on resistance of austentic SS via elevated austenite formation. It was suggested and believed that an important role in this mechanism is the fabric sputtered from the active display and then redeposited onto the specimens. There is a great correlation between this patterned deposited layer and the grain orientation of poly-crystalline specimens which gave a further insights into the nitriding mechanisms. AISI 904L were explored by plasma hardening method through this current work. The hardness of the studied material was found to be enhanced from $291 \mathrm{Hv}$ to $1021 \mathrm{Hv}$. On comparing with the untreated specimen whose wear loss is around 0.92 gm, very less wear loss of about $0.1 \mathrm{gm}$ was obtained through this wear test. An extended austenite layer was fashioned on the surface of the surface with thickness ranging from 2 to $27 \mu \mathrm{m}$.

\section{References:}

1. F. Bottoli, M.S. Jellesen, T.L. Christiansen, G. Winther, M.A.J. Somers, Appl. Surf. Sci. 431 (2018).

2. H.P.Van Landeghem, M.Goune, A.Redjaimia, Journal of crystal growth, 341, 1(2012)

3. J. Biehler, H. Hoche, M. Oechsner, Surf. Coatings Technol. 313 (2017)

4. I.Alphonsa, A.Chainani, PM.Raole, B.Ganguli, PI.John, Surface Coatings and Technology, 150, (2002).

5. Q. Chao, V. Cruz, S. Thomas, N. Birbilis, P. Collins, A. Taylor, P.D. Hodgson, D. Fabijanic, Scr. Mater. 141 (2017)

6. N. Chen, G. Ma, W. Zhu, A. Godfrey, Z. Shen, G. Wu, X. Huang, Mater. Sci. Eng. A. 759 (2019).

7. J.Baranowska, Pawel Kochmanska, Wear, 278 (2012).

8. M.G. Shahri, M. Salehi, S.R. Hosseini, M. Naderi, Surf. Coatings Technol. 310 (2017).

9. Rajagiri A, MN Sandhya, Nawaz S, Suresh Kumar Tummala, E3S Web of Conferences 8701004 (2019).

10. Y.M. Wang, T. Voisin, J.T. McKeown, J. Ye, N.P. Calta, Z. Li, Z. Zeng, Y. Zhang, W. Chen, T.T. Roehling, R.T. Ott, M.K. Santala, P.J. Depond, M.J. Matthews, A. V.Hamza, T. Zhu, Nat. Mater. 17 (2018).

11.Md Sumair Ur Rahman, L.Jayahari, Materials Today: Proceedings, 5, 9 (2018)

12. Lade Jayahari, Banoth Balunaik, Amit Kumar Gupta, Swadesh Kumar Singh, Materials Today:Proceedings, 2, (2015)

13. Ratna Deepika Manikonda, Satyanarayana kosaraju, K. Arul Raj, N.Sateesh,, Materials Today: Proceedings, 5,9 (2018)

14. M.J.K. Lodhi, K.M. Deen, M.C. Greenlee-Wacker, Addit. Manuf. 27 (2019)

15.A.Popelka, I. Novák, M.A.S.A. Al-Maadeed, M. Ouederni, I. Krupa, Surf. Coat. Technol. 335 (2018)

16. Tummala Suresh Kumar, Kosaraju Satyanarayana, Materials Today: Proceeding, 26(2020).

17.Lopez HSM, Moreto JA, Manfrinato MD, Cruz NC, Rangel EC,Rossino LS, Mater Res 19 (2016).

18. Baloji, D., Anil, K., Satyanarayana, K., Singh, S. K., \& Naik, M. T. Material Today 18, 4475-4481. (2019).

19.J.Dutta Majumdar, J.Alphonsa, A.Basu, Wear, 62 (2008)

20.J.Lebrun, L.Poirer, D.Hertz, C.Lincot, Surface Engineering, 18 (2002).

21.J.Miola Eduardo, Gontijo Leonardo, Machado Rrogerio, Vacuum science and Technology, 21 (2003).

22.J.Spies, C.Eckstein, H.Zenders, Surface Engineering, 18 (2002).

23.J.Takada, Y.Ohizumi, H.Miyamura, H.Kuwahara, S.Kikuchi, I.Tamura, Journal of Material Science, 21 (1986) 